\title{
ПРОБЛЕМИ ВПРОВАДЖЕННЯ ЦИФРОВИХ ТЕХНОЛОГІЙ («ШТУЧНОГО ІНТЕЛЕКТУ») У ПРОЦЕСІ СТВОРЕННЯ РОБОТИЗОВАНОГО СЦЕНІЧНОГО ОБРАЗУ
}

\section{Тетяна Совгира}

кандидат мистецтвознавства;

e-mail: stisovgyra@gmail.com; ORCID: 0000-0002-7023-5361

Київський національний університет культури і мистецтв, Київ, Україна

\begin{abstract}
Анотація
Мета дослідження полягає у визначенні, аналізі та систематизації наявного досвіду використання цифрових технологій, що нині іменуються "штучним інтелектом», у процесі створення видовищ. Відповідно до визначеної мети заплановано розв'язання таких взаємопов'язаних завдань: сформулювати основний понятійно-категоріальний апарат із цієї тематики; визначити функціональну складову діяльності механізованих організмів (роботів) щодо їх можливого застосування у видовищних заходах; простежити й узагальнити досвід використання цифрових технологій, зокрема «штучного інтелекту», у процесі створення роботизованого сценічного образу. Методологія дослідження базується на комплексному підході та спирається на поєднання кількох методів: аналітичного - під час розгляду історичної, філософської, культурологічної та мистецтвознавчої літератури з предмета дослідження; теоретично-концептуального методу - під час аналізу понятійно-термінологічної системи дослідження та виявлення особливостей упровадження технології «штучного інтелекту» в процесі створення видовищних форм;порівняльно-типологічного-дляпорівняння специфіки функціонування механізованих «акторів» з акторською майстерністю людей-акторів. Наукова новизна роботи полягає в тому, що вперше розглянуто специфіку використання цифрових технологій, зокрема штучного інтелекту, у процесі створення сценічного видовища. Висновки. Виявлено, що автономія роботизованих механізмів можлива, адже новітні моделі роботів здатні сканувати простір, осіб навколо себе та за певним алгоритмом реагувати в потрібний момент. Ці можливості наближують андроїда до реального актора в сценічному просторі. Імпровізація як характерна особливість акторської майстерності буде являти собою прояв автономності дій і «реакцій» роботів. Роботизований механізм у сценічному просторі $є$ експериментальнодослідницькою платформою. Проєкти спрямовані на вивчення можливостей функціонування роботизованої техніки в умовах сценічного простору, специфіки взаємодії людської та механізованої діяльності, а заразом - дослідження питань соціальної футурології. Робот вповні може функціонувати як унікальний технічний інваріант актора-виконавця в сценічній постановці чи артінсталяції.
\end{abstract}

Ключові слова: цифрова технологія; театр; штучний інтелект; робот; актор 


\section{Постановка проблеми}

На сучасному етапі українське мистецтво переживає технологічну модернізацію. Трансформаційні процеси, пов'язані з технічним прогресом у суспільстві, детермінують зміну специфіки усталених художніх напрямів і появу синтетичних мистецьких новоутворень. Технічні інновації проникають і в сценічний простір: створюються інтерактивні вистави із застосуванням цифрових технологій, світлові та голографічні шоу-програми, візуальні інсталяції тощо. Однак серед усіх креативних винаходів найбільш інноваційною $€$ технологія «штучного інтелекту», за допомогою якої створюють роботизовані механізми, що давно вже використовують у сценічному просторі як актора-виконавця.

\section{Аналіз останніх досліджень і публікацій}

Проблему технічних інновацій у сценічному мистецтві описано у вітчизняних наукових розвідках Г. Липківської (2018), К. Юдової-Романової, Ю. Аленіної(2019), В. Стрельчук, Ю. Чубукової (2019) та інших. Однак автори не приділяють уваги проблемі впровадження технології «штучного інтелекту» в сценічному просторі.

Натомість у закордонних працях це питання часто порушують, зокрема автори розглядають досвід європейських і східних театральних установ у використанні роботизованих механізмів як акторів-виконавців. Японська дослідницяЮ. Санна прикладі комедійної вистави «Бакаробо» (постановники: М. Денкі (Meiwa Denki), агенція Йошімото Креатів (Yoshimoto Creative Agency), Токіо, 2007-2008рр.) досліджує функціональну складову роботизованих механізмів у процесі організації театрального видовища. А. Волков у праці «Робототехнічні та мехатронні системи театральної машинерії» (2007) досліджує технологічну складову театральної машинерії. С. Колтон та Г. Віггінс (Colton and Wiggins, 2012), Х. Найт (Knight, 2011, pp.42-51), А. Легерська (Legierska, 2014) аналізують можливість використання роботів у масовій культурі.

Водночас ці питання мають здебільшого дискусійний характер. У дослідженнях 3. Паре (Paré, 2015), Х. Парсонс та Г. Керслі (Parsons and Kearsley, 1982, pp.535552) вказано, що роботизовані механізми на сцені можуть виконувати лише запрограмовані маніпуляції, натомість науковці С. Колтон, Г. Віггінс та Дж. Мьонхун (Myounghoon, 2017, p.5) наполягають на автономності та можливості «імпровізації» андроїдів в умовах сценічного простору. Детальний огляд функціонування механізованих систем подано у фундаментальних працях видатних математиків Н. Вінера (1983) та В. Глушкова (1964), М. Новотарського та Б. Нестеренка (2004).

Аналіз літератури з обраної тематики засвідчує наявність різноманіття думок щодо проблеми впровадження технології «штучного інтелекту» у сценічному мистецтві, принципів організації роботизованих вистав і ролі механізованих «акторів» у процесі створення сценічного видовища. Визначені питання свідчать про нагальну необхідність дослідження функціонування цієї технології в межах сценічного простору.

Мета дослідження. На основі аналізу наявних театральних постановок і перфомансів, створених з використанням технологій «штучного інтелекту», та дже- 
рельної бази з відповідної теми дослідження з'ясувати проблеми впровадження цифрових технологій («штучного інтелекту») у процесі створення роботизованого сценічного образу. Досягнення поставленої мети передбачає розв'язання таких взаємопов'язаних завдань: сформулювати основний понятійно-категоріальний апарат із цієї тематики; визначити функціональну складову діяльності механізованих організмів (роботів) щодо їх можливого застосування в театральновидовищних заходах; простежити й узагальнити досвід використання «штучного інтелекту» в організації театрально-видовищних заходів.

\section{Виклад основного матеріалу}

З часів античності людство постійно перебуває в пошуках унікальної технології, яка б спрощувала виробничу та творчу діяльність. Згадаймо про персонажа з єврейської міфології Голема, якого за легендою створили рабини-кабалісти. Цей персонаж з єврейської міфології начебто виконував певні дії після «програмування» його кабалістичними заклинаннями. У разі збою такого «програмування» Голем трощив усе навколо. Ця антична легенда створення певного винаходу, а також його програмування (кодування) стала можливою в умовах сучасного світу. Нині технологія, яку заведено називати «штучний інтелект», не є легендою і навіть вигадкою, а являє собою реалію, створену на основі IT-розробок сучасних інженерів та конструкторів.

Леонардо да Вінчі ще у 1495 році створює ескізи робота, який за будовою схожий на людину та повинен функціонально відтворювати її діяльність. Учений називає свій механізм «автоматом». Однак невідомо, чи був реалізований той ескіз, як й інші нариси винаходів науковця та митця Леонардо да Вінчі.

Відтоді думка про створення роботизованої техніки, яка б полегшувала людську діяльність, не полишає науковців. У дзеркалі наукової критики з'являється поняття «естетичне обчислення» (з англ. "aesthetic computing»), що являє собою системний підхід до вивчення взаємовідносин між інноваційними цифровими технологіями та мистецтвом, «застосування теорії і практики мистецтва до обчислювальної техніки» (Shem-Shaul, et al., 2003). Згідно з цими дослідженнями цифрові й обчислювальні технології впливають на мистецтво та естетику, розширюючи наші виміри сприйняття, у той час як мистецтво й естетика також впливають на цифрові технології, розширюючи уявлення про обчислювальний процес.

Згодом до цифрових розробок посилюється інтерес і з боку масової культури. Використання технології «штучного інтелекту» стає можливою на сценічних підмостках. Зокрема, роботизована техніка з'явилася у двадцятихвилинній виставі «Я, працівник» (2008р., м. Осака, Японія), що створена за мотивами п'єси японського драматурга Орідзи Хірата (Nishiguchi et al., 2017, pp.158-166).

Роботи були запрограмовані проговорювати текст у конкретні моменти, переміщуватися та здійснювати певні маніпуляції відповідно до сюжетної лінії вистави. Однак цей випадок засвідчив, що саме тоді робот не міг зрівнятися з людиною у виконавських здібностях. Адже акторська майстерність передбачає вміння переконати глядача в правдивості та реалістичності створеного акторського образу. Механізований організм не міг виконати цю функцію, натомість надавав 
Вісник Київського національного університету культури і мистецтв.

Серія: Сценічне мистецтво

дійству надзвичайну видовищність та оригінальність подачі змістового матеріалу п'єси.

Згодом у сценічній практиці здійснюють експериментальні спроби програмування роботизованої техніки за допомогою технології «штучного інтелекту». Роботи на сцені почали повторювати рухи реальних акторів, завдяки чому створювалася ілюзія взаємодії реальних і механізованих акторів. За допомогою алгоритмічного аналізу роботизовані організми нині можуть сканувати дії об'єктів і на основі отриманих даних здійснювати власні операції (Совгира, 2020). У цьому разі діяльність роботизованого механізму може дати унікальні результати, які людина не передбачає.

Англійська компанія "Engineered Arts» створила у 2014 р. RoboThespian - першого у світі робота-актора, який на відміну від своїх попередників був дуже схожим на людину та здатним повторювати рухи реальних акторів. За допомогою технології захоплення руху («motion capture») механізм міг імітувати рухи будького в аудиторії. Ця особливість стала можливою завдяки наявності в корпусі «механізованого актора» датчиків сканування та аніматроніка. У такий спосіб роботи сканували мову тіла, вік, настрій людей, які їх оточують, та могли реагувати відповідно. Робот міг читати текст і додавати відповідне вираження обличчя (інтерфейсу), співати, танцювати, не відчуваючи фази страху.

Спочатку RoboThespian у театральній справі використовували лише як «гіда» в театрі, який повинен був запрошувати глядачів до перегляду, інформувати їх щодо змісту вистави та пропонувати програми запланованої вистави. Перша партія складалася всього з п'ятнадцяти роботів, які миттєво розкупили адміністративні групи театрів, університетів і музеїв. Невдовзі інноваційна техніка зацікавила й режисерсько-постановочну групу. Так, у 2013 р. поставили виставу «Зловісна долина» («Uncally Valley») Франчески Таленті (F. Talenti) (Італія) з використанням RoboThespian на сценічних підмостках. В основу фантастичного сюжету покладено історію людини, яка погоджується завантажити свою особистість у робота в обмін на гроші. Тож використання робота в сценічній постановці цілком виправдовує розвиток подій у п'єсі. Сам режисер-початківець зізнався, що працювати з технологією «штучного інтелекту» було непросто через несвоєчасну реакцію та неприродність дій роботизованого гаджета. 32017 р. вистава «Спілікін» («Spillikin») театру «Пайплін» («Pipeline») в Единбурзі також проходить за участі RoboThespian (Hickey, 2014).

У результаті аналізу специфіки функціонування RoboThespian виявлено, що робота сучасного роботизованого механізму на сцені має кілька переваг над людською виконавською діяльністю. По-перше, за функціональною складовою винахід $є$ ефективнішим та економнішим, адже йому не потрібні перерви на сон, харчування чи відпочинок. По-друге, «механізованого робота» можна запрограмувати на дії та промову будь-якою мовою, отже, такий «працівник» $є$ універсальним. Пізні версії роботів демонструють більш ніж 30 варіацій руху й емоцій, що достатньою мірою доповнює текст. Робот може функціонувати за будь-яких погодних умов (навіть під дощем).

Водночас для «гри на сцені» важливою є взаємодія з глядачем і партнером. Натомість робот «Engineered Arts» може тримати зоровий контакт зі співрозмов- 
ником завдяки наявності відповідних датчиків сканування. Ця функція надає механізованому роботу особливість телеприсутності.

у процесі дослідження переходимо від аналізу конкретних особливостей функціонування роботів у сценічному просторі до з'ясування більш глибоких питань мистецтвознавчого аспекту, в тому числі - до аналізу можливого спілкування та взаємодії роботизованого організму з реальним актором на сценічних підмостках.

На нашу думку, нині вже є кілька проєктів, в яких створено ілюзію безпосереднього спілкування між актором і роботом. Японський режисер X. Ішігуро (H. Ishiguro) в експериментальному театральному проєкті «Актор-робот» («Robot Actor») спробував показати, як люди та механізми можуть розмірковувати над соціально-культурними проблемами в майбутньому (Паре, 2015, с.143162). Дивоглядно, що в цій виставі роботи чи не вперше мали «грати» різні ролі (робот-«людина», робот-«тварина» тощо) й активно взаємодіяти з партнерами та навколишнім середовищем (робити рукостискання, грати у футбол, повертатися до співрозмовника, змінювати локації). Таким чином у дійстві створювалась ілюзія, що для роботів можлива часткова свобода волі та автономія (імпровізація). За словами розробників К. Огави, К. Таури та Х. Ішігуро, на глядацьку аудиторію справляли більші враження виступи андроїдів, аніж номери реальних акторів (Ogawa, Taura and Ishiguro, 2012, с.565-570). Схожі експериментальні спроби взаємодії, спілкування та навіть любовних перипетій між актором і машиною спостерігаємо у виставі «Спілікін» («Spillikin», 2017 р.) театру «Пайплін» («Pipeline») в Единбурзі.

Науковець Е. Найт (Knight, 2011, с.42-51) визначила критично важливі компоненти для кращого програмування роботів для театральних підмостків: здійснення відповідних жестів, вираження емоцій, метафори руху, спілкування із зовнішніми емоціями, соціальний інтелект, зворотний зв'язок з аудиторією та машинний гумор. Роботи мають здійснювати рухи та змінювати інтонаційно голос для кращої передачі відповідних емоцій.

Ці поодинокі випадки використання роботів у театральних постановках засвідчують можливість і необхідність залучення технології «штучного інтелекту» в сценічний простір. Однак вартість таких експериментів є вкрай високою. На нашу думку, через це прояви впровадження штучного інтелекту в театрі $€$ поодинокими. Нині один робот коштує понад вісімдесят тисяч доларів.

Наукова новизна роботи полягає в тому, що вперше розглянуто специфіку використання цифрових технологій, зокрема штучного інтелекту, у процесі створення сценічного видовища.

\section{Висновки}

У результаті проведеного дослідження виявлено часткову самостійність роботів, яких заздалегідь запрограмувала людина. Автономія роботизованих механізмів можлива, адже новітні моделі роботів здатні сканувати простір, осіб навколо себе та за певним алгоритмом реагувати в потрібний момент. Ці можливості наближують андроїда до реального актора в сценічному просторі. Ім- 
провізація як характерна особливість акторської майстерності буде являти собою прояв автономності дій та «реакцій» роботів.

Роботизований механізм у сценічному просторі є експериментально-дослідницькою платформою. Проєкти спрямовані на вивчення можливостей функціонування роботизованої техніки в умовах сценічного простору, специфіки взаємодії людської та механізованої діяльності, а заразом - дослідження питань соціальної футурології. 3'ясовано, що технологію «штучного інтелекту» в сценічних постановках активно використовують режисери Англії, Шотландії, Польщі, Японії та Китаю. Однак ці поодинокі випадки використання роботів у театральних постановках засвідчують можливість і необхідність залучення технології «штучного інтелекту» в сценічний, зокрема український, простір. Незважаючи на високу вартість технічних експериментів, андроїди на сцені мають значні перспективи впровадження в Україні. Робот вповні може функціонувати як унікальний технічний інваріант актора-виконавця в сценічній постановці чи артінсталяції.

\section{СПИСОК ПОСИЛАНЬ}

Винер, Н., 1983. Кибернетика или управление и связь в животном и машине. Москва: Наука. Глушков, В.М., 1964. Введение в кибернетику. Киев: АН УССР.

Липківська, Г., 2018. Мультимедійні засоби на сучасній театральній сцені. Вісник Київського національного університету культури і мистецтв. Серія: Сценічне мистецтво, 1, с.103-115. doi: https://doi.org/10.31866/2616-759x.1.2018.144964

Новотарський, М.А. та Нестеренко, Б.Б., 2004. Штучні нейронні мережі: обчислення. Праці Інституту математики НАН України, 50.

Совгира, Т.І., 2020. Принципи використання цифрових технологій в культурно-мистецькій практиці. Культура і сучасність, 1, с.39-42.

Чубукова, О.Ю., 2015. Кібернетика: від простих систем та технологій до кіберсередовища. Актуальні проблеми економіки, 12, с.33-28.

Юдова-Романова, К. та Аленіна, Ю., 2019. Модернізація театрального простору: сучасний вітчизняний мистецтвознавчий контекст. Народознавчі зошити, 1 (145), с.259-265.

Юдова-Романова, К., Стрельчук, В. та Чубукова, Ю., 2019. Режисерські інновації у використанні технічних засобів і технологій у сценічному мистецтві. Вісник Київського національного університету культури і мистецтв. Серія: Сценічне мистецтво, 2(1), с.52-72. doi: 10.31866/2616-759x.2.1.2019.170749

Belezina, J., 2011. Robothespian humanoidní robotpřináší lidské představení. Robotika. [online] Доступно: <https://cs.inforandum.com/robothespian-humanoid-robot-delivers-human-likestage-performances-88348> [Дата звернення 15 квітня 2021].

Bruce, A., Knight, J., Listopad, S., Magerko, B. and Nourbakhsh, I.R., 2000. Robot improv: Using drama to create believable agents. In: Proceedings of the IEEE International Conference on Robotics and Automation (ICRA'00), pp. 4002-4008.

Colton, S. and Wiggins, G.A., 2012. Computational creativity: The final frontier? In: Proceedings of the 20th European Conference on Artificial Intelligence, pp. 21-26.

Hickey, S., 2014. RoboThespian: the first commercial robot that behaves like a person. [online] Available at: <https://www.theguardian.com/technology/2014/aug/17/robothespianengineered-arts-robot-human-behaviour> [Accessed 10 March 2021]. 
Knight, H., 2011. Eight lessons learned about non-verbal interactions through robot theater. In: Proceedings of the International Conference on Social Robotics, pp.42-51.

Legierska, A., 2014. The Rise of Robotic Theatre. Culture. [online] Available at: <https://culture.pl/ en/article/the-rise-of-robotic-theatre> [Accessed 10 March 2021].

Myounghoon, J., 2017. Robotic Arts: Current Practices, Potentials, and Implications Multimodal Technologies Interact, 1(2), p.5. doi:10.3390/mti1020005

Nishiguchi, S., Ogawa, K., Yoshikawa, Y., Chikaraishi, T., Hirata, O. and Ishiguro, H., 2017. Theatrical approach: Designing human-like behaviour in humanoid robots. Robotics and Autonomous Systems, 89, pp.158-166.

Ogawa, K., Taura, K. and Ishiguro, H., 2012. Possibilities of androids as poetry-reciting agent. In: Proceedings of the 21st IEEE International Symposium on Robot and Human Interactive Communication, pp.565-570.

Paré, Z., 2015. Robot actors: Theatre for robot engineering. Theatres du Posthumain, pp. 143-162. Parsons, H.M. and Kearsley, G.P., 1982. Robotics and human factors: Current status and future prospects. Human Factors: The Journal of the Human Factors and Ergonomics Society, 24, pp.535552. doi: $10.1177 / 001872088202400504$.

Reeve, J., 2014. Understanding Motivation and Emotion. Wiley: Hoboken.

Shem-Shaul, N.B., Bertelsen, O.W., Bolter, J., Bruns, W., Bureaud, A., Diehl, S., Dombois, F., Ebert, A., Edmonds, E. and Entacher, K., 2003. Aesthetic computing manifesto. Proceedings of the Dagstuhl Workshop on Aesthetic Computing. Germany.

Sone, Yu., 2012. Double Acts: human-robot performance in Japan's Bacarobo Theatre. London: Cambridge.

\section{REFERENCES}

Belezina, J., 2011. Robothespian humanoidní robotpřináší lidské představení. Robotika. [online] [online] Available at: <https://cs.inforandum.com/robothespian-humanoid-robot-delivershuman-like-stage-performances-88348> [Accessed 15 April 2021].

Bruce, A., Knight, J., Listopad, S., Magerko, B. and Nourbakhsh, I.R., 2000. Robot improv: Using drama to create believable agents. In: Proceedings of the IEEE International Conference on Robotics and Automation (ICRA'00), pp.4002-4008.

Chubukova, O.lu., 2015. Kibernetyka: vid prostykh system ta tekhnolohii do kiberseredovyshcha [Cybernetics: from simple systems and technologies to cybertressing]. Aktualni problemy ekonomiky, 12, pp.33-28.

Colton, S. and Wiggins, G.A., 2012. Computational creativity: The final frontier? In: Proceedings of the 20th European Conference on Artificial Intelligence, pp. 21-26.

Glushkov, V.M., 1964. Vvedenie v kibernetiku [Introduction to cybernetics]. Kyiv: National Academy of Sciences of Ukraine.

Hickey, S., 2014. RoboThespian: the first commercial robot that behaves like a person. Support the Guardian. [online] Available at: <https://www.theguardian.com/technology/2014/ aug/17/robothespian-engineered-arts-robot-human-behaviour > [Accessed $10 \mathrm{March}$ 2021].

ludova-Romanova, K. and Alenina, Yu., 2019. Modernizatsiia teatralnoho prostoru: suchasnyi vitchyznianyi mystetstvoznavchyi kontekst [Modernization of theatrical space: modern domestic art criticism]. Narodoznavchi zoshyty, 1 (145), pp.259-265. 
ludova-Romanova,K.,Strelchuk,V.andChubukova,Yu.,2019. Rezhyserskiinnovatsiiuvykorystanni tekhnichnykh zasobiv i tekhnolohii u stsenichnomu mystetstvi [Directorate innovations in the use of technical means and technologies in stage art]. Bulletin of Kyiv National University of Culture and Arts. Series in Stage Art, 2(1), pp.52-72. doi: 10.31866/2616-759x.2.1.2019.170749.

Knight, H., 2011. Eight lessons learned about non-verbal interactions through robot theater. In: Proceedings of the International Conference on Social Robotics, pp.42-51.

Legierska, A., 2014. The Rise of Robotic Theatre. Culture. [online] Available at: <https://culture.pl/ en/article/the-rise-of-robotic-theatre> [Accessed 10 March 2021].

Lypkivska, H., 2018. Multymediini zasoby na suchasnii teatralnii stseni [Multimedia on the modern theater stage]. Bulletin of Kyiv National University of Culture and Arts. Series in Stage Art, 1, pp.103-115. doi: https://doi.org/10.31866/2616-759x.1.2018.144964.

Myounghoon, J., 2017. Robotic Arts: Current Practices, Potentials, and Implications. Multimodal Technologies Interact, 1(2), p.5. doi:10.3390/mti1020005.

Nishiguchi, S., Ogawa, K., Yoshikawa, Y., Chikaraishi, T., Hirata, O. and Ishiguro, H., 2017. Theatrical approach: Designing human-like behaviour in humanoid robots. Robotics and Autonomous Systems, 89, pp.158-166.

Novotarskyi, M.A. and Nesterenko, B.B., 2004. Shtuchni neironni merezhi: obchyslennia [Artificial neural networks: computation]. Pratsi Instytutu matematyky NAN Ukrainy, 50.

Ogawa, K., Taura, K. and Ishiguro, H., 2012. Possibilities of androids as poetry-reciting agent. In: Proceedings of the 21st IEEE International Symposium on Robot and Human Interactive Communication, pp.565-570.

Paré, Z., 2015. Robot actors: Theatre for robot engineering. Theatres du Posthumain, pp.143-162. Parsons, H.M. and Kearsley, G.P., 1982. Robotics and human factors: Current status and future prospects. Human Factors: The Journal of the Human Factors and Ergonomics Society, 24, pp.535552. doi: 10.1177/001872088202400504.

Reeve, J., 2014. Understanding Motivation and Emotion. Wiley: Hoboken.

Shem-Shaul, N.B., Bertelsen, O.W., Bolter, J., Bruns, W., Bureaud, A., Diehl, S., Dombois, F., Ebert, A., Edmonds, E. and Entacher, K., 2003. Aesthetic computing manifesto. Proceedings of the Dagstuhl Workshop on Aesthetic Computing. Germany.

Sone, Yu., 2012. Double Acts: human-robot performance in Japan's Bacarobo Theatre. London: Cambridge.

Sovhyra,T.I.,2020. Pryntsypy vykorystanniatsyfrovykhtekhnolohiivkulturno-mystetskiipraktytsi [Principles of using digital technologies in cultural and artistic practice]. Kultura i suchasnist, 1, pp.39-42.

Viner, N., 1983. Kibernetika ili upravlenie i sviaz v zhivotnom i mashine [Cybernetics or management and contact in the animal and car]. Moscow: Nauka. 


\section{ПРОБЛЕМЫ ВНЕДРЕНИЯ НОВЕЙШИХ ЦИФРОВЫХ ТЕХНОЛОГИЙ («ИСКУССТВЕННОГО ИНТЕЛЛЕКТА») В ПРОЦЕССЕ СОЗДАНИЯ РОБОТИЗИРОВАННОГО СЦЕНИЧЕСКОГО ОБРАЗА}

\section{Татьяна Совгира}

кандидат искусствоведения;

e-mail: stisovgyra@gmail.com; ORCID: 0000-0002-7023-5361

Киевский национальный университет культуры и искусств, Киев, Украина

\section{Аннотация}

Цель исследования заключается в определении, анализе и систематизации имеющегося опыта использования цифровых технологий, именующихся «искусственным интеллектом», в процессе создания зрелищ. Согласно определенной цели запланировано решение следующих взаимосвязанных задач: сформулировать основной понятийнокатегориальныйаппаратподаннойтематике;определитьфункциональнуюсоставляющую деятельности механизированных организмов (роботов) относительно их возможного применения в зрелищных мероприятиях; проследить и обобщить опыт использования цифровых технологий, в частности «искусственного интеллекта», в процессе создания роботизированного сценического образа. Методология исследования базируется на комплексномподходеиопираетсянасочетаниенесколькихметодов:аналитического-при рассмотрении исторической, философской, культурологической и искусствоведческой литературы по предмету исследования; теоретико-концептуального метода - при анализе понятийно-терминологической системы исследования и выявлении особенностей внедрения технологии «искусственного интеллекта» в процессе создания зрелищных форм; сравнительно-типологического - для сравнения специфики функционирования механизированных «актеров» с актерским мастерством людейактеров. Научная новизна работы заключается в том, что впервые рассматривается специфика использования цифровых технологий, в частности искусственного интеллекта, в процессе создания сценического зрелища. Выводы. Выявлено, что автономия роботизированных механизмов возможна, ведь новейшие модели роботов способны сканировать пространство, людей вокруг себя и по определенному алгоритму реагировать в нужный момент. Эти возможности приближают андроида к реальному актеру в сценическом пространстве. Импровизация как характерная особенность актерского мастерства будет представлять собой проявление автономности действий и «реакций» роботов. Роботизированный механизм в сценическом пространстве является экспериментально-исследовательской платформой. Проекты направлены на изучение возможностей функционирования роботизированной техники в условиях сценического пространства, специфики взаимодействия человеческой и механизированной деятельности, а вместе с тем - исследование вопросов социальной футурологии. Робот полностью может функционировать как уникальный технический инвариант актераисполнителя в сценической постановке или арт-инсталляции.

Ключевые слова: цифровая технология; театр; искусственный интеллект; робот; актер 


\title{
PROBLEMS OF INTRODUCING DIGITAL TECHNOLOGIES ("ARTIFICIAL INTELLIGENCE") IN THE PROCESS OF CREATING ROBOTIC STAGE IMAGE
}

\section{Tetiana Sovhyra}

\author{
Ph.D. in Art History; \\ e-mail: stisovgyra@gmail.com; ORCID: 0000-0002-7023-5361 \\ Kyiv National University of Culture and Arts, Kyiv, Ukraine
}

\begin{abstract}
The purpose of the article is to identify, analyse and systematize the existing experience of using digital technologies, now called "artificial intelligence", in the process of creating spectacles. According to a specific goal, it is planned to solve the following interrelated tasks: to formulate the basic conceptual and categorical apparatus on this topic; to determine the functional component of the activity of mechanized organisms (robots) in relation to their possible use in entertainment events; trace and summarize the experience of using digital technologies, in particular, "artificial intelligence" in the process of creating a robotic stage image. The research methodology is based on an integrated approach and relies on a combination of several methods: analytical is to considering the historical, philosophical, cultural and art history literature on the subject of research; theoretical and conceptual method are to analyse the conceptual and terminological system of research and identifying the features of the introduction of AR technology in the process of creating spectacular forms; comparative typological is to compare the specifics of the functioning of mechanized "actors" with the acting skills of human actors. The scientific novelty of the work lies in the fact that for the first time the specifics of the use of digital technologies, in particular artificial intelligence, in the process of creating a stage show has been considered. Conclusions. It has been revealed that the autonomy of robotic mechanisms is possible, because the latest models of robots are able to scan space, a person around them and, according to a certain algorithm, react at the right time. These capabilities bring the android closer to the real actor in the stage space. Improvisation as a characteristic feature of acting will be a manifestation of the actions autonomy and "reactions" of robots. The robotic mechanism in the stage space is an experimental research platform. The projects are aimed at studying the possibilities of the functioning of robotic technology in the conditions of the stage space, the specifics of the human interaction and mechanized activity, and at the same time - the study of social futurology issues. The robot can fully function as a unique technical invariant of an actor performer in a stage production or art installation.
\end{abstract}

Keywords: digital technology; theatre; artificial intelligence; robot; actor 